\title{
Self-Reported and Objectively Measured Physical Activity of Males from 50 to 69 Years Old
}

\author{
Jovan Radulovic ${ }^{1}$ \\ ${ }^{1}$ University of Montenegro, Faculty for Sport and Physical Education, Niksic, Montenegro
}

\begin{abstract}
The main goal of this study was to check the physical activity of men aged 50 to 69 years. The research involved 100 of them, where they were divided into two subunits, of which the first subunit was composed of 73 men, aged 50 to 59, and the second sub-adult of 27 men, who had between 50 and 69 years of age. A longer version of the international IPAQ questionnaire was used as the measuring instrument of this research, which contained four types of physical activity (business, transportation, household and leisure) through three levels of physical activity (low, medium and moderate). The results showed that physical activity in free time is not sufficiently represented, and that leisure time for recreation purposes is significantly less than expected. Likewise, physical activities for the purpose of transport are significantly lower than expected. The research has proven that the younger sub-examinees of the respondents are more physically active than the elderly, which is due to the fact that the physical activity of elderly people has been declining over the years.
\end{abstract}

Key words: Physical Activity, 50-69 years, Male, IPAQ Questionnaire

\section{Uvod}

Čovjekovo bavljenje svim vidovima fizičke kulture, u onom smislu u kojem se oni danas shvataju, počelo je mnogo prije nego sto su ti pojmovi verbalno definisani (Bjelica i Krivokapić, 2010). Fizička aktivnost u primarnom smislu je jedan od najvažnijih koraka u poboljšanju zdravlja. To je činjenica koju je svaki pojedinac makar jednom čuo, međutim, nažalost veći je broj onih koji je ne slijede. Neuredan način života, prije svega, misli se na neredovan san, manjak fizičke aktivnosti i nepravilna ishrana su glavni faktori za nastanak hroničnih bolesti čovjeka. Kao na primjer: visok krvni pritisak, gojaznost, povišeni holesterol, dijabetes i depresivno ponašanje (Bjelica, 2004; Bjelica i Krivokapić, 2011).

Svako razvojno razdoblje ima svoja obilježja po kojima se razlikuje od drugih razvojnih razdoblja, te na osnovu toga čovjek ih mora prepoznati kako bi mogao reagovati na određene promjene (Findak, 2001). Smanjene funkcionalne sposobnosti (snage, izdržljivosti, sposobnosti i fleksibilnosti) prouzrokovano procesom starenja, izaziva poteškoće u svakodnevnim fizičkim aktivnostima i normalnom funkcionisanju starijih osoba (Milanović, Pantelić, Sporiš, Krakan, \& Mudronja, 2012).
Analogno tome, treba raditi na podsticanju svih, bez obzira na starosnu dob, da se aktivno bave fizičkim vježbanjem, kako sopstvene fizičke sposobnosti ne bi nazadovale (Bjelica, 2006b). U Crnoj Gori još uvijek nije dovoljno zaživljela svijest o značaju vježbanja, već je u hijerarhiji dnevnih aktivnosti, rekreacija na posljednjem mjestu. Aktuelni trend, odnosno brži način života, dovodi do ovakvog zaključka. Jasno je da današnji čovjek sve manje ima slobodnog vremena, jer ispred sebe stavlja novac, a ne zdravlje, dok na suprotnoj strani je sve više osoba zarobljenih tehnologijom koja rapidno raste i deprimira njene korisnike da žive zdravim životom. Čini se da moderan tehnološki „smart“ život ne utiče na osobe trećeg doba, da imaju više slobodnog vremena i da ih vrijeme za sprovođenje fizičke aktivnosti (rekreacije) nije zaobišlo, opet, shodono njihovim godinama, mnoga istraživanja pokazuju da i njihov nivo fizičke značajno aktivnosti opada.

Nesumnjivo da koncentracija stanovništva u gradskim područjima, manje zelenih površina, napuštanje seoskih gazdinstava i dolazak u gradska urbana jezgra, uslovljava mlađi, a kamoli stariji stalež na smanjeno kretanje. S toga, za ovu populaciju je isto takođe važno, stvoriti pristupačne sadržaje i lokacije zelenih

Correspondence:

Montenegro J.Radulovic

Gport University of Montenegro, Faculty for Sport and Physical Education, Narodne omladine bb, 81400, Niksic, Montenegro E-mail: jovanradulovicradule@gmail.com 
(zdravih) površina sa adekvatnim mobilijarom, da bi na pravi način bili motivisani kako oni tako i čitavo društvo (Bjelica, 2002, 2005). Zajednička fizička aktivnost u grupama pomaže starijim ljudima da se upoznaju sa drugima, prošire svoju društvenu mrežu poboljšaju svoje zdravlje. Fizička aktivnost ima veliki uticaj na socijalizaciju starijih, zapravo može služiti za smanjenje socijalne isključenosti starijih ljudi, proširenje društvene mreže i poboljšanje njihovog zdravlja (Popović i Bjelica, 2017).

Uvjerenja govore, da redovna fizička aktivnost upražnjavana od malih nogu, donose benefite koji se najbolje ogledaju u trećem dobu života. Sto znači da aktivne osobe grade i jačaju čitav psihosomatski status, imaju samim tim zdrave i pozitivne poglede na okolinu, zrače energijom i osjećaju se korisnim u društvu. Dok na drugoj strani, imamo osobe koje „utučene“ neurednim načinom života, nedovoljnim oslobađanjem „negativne“ energije kroz rekreaciju, emituju uglavnom loše vibracije na okolinu, što se svakako prenosi i na njihov organizam (Bjelica, 2006a; 2013). U velikom broju istraživanja je potvrđeno da starije osobe koje ostanu fizički aktivne imaju veće nivoe snage nego sedentarne osobe, što sve upućuje na povezanost fizičke aktivnosti i psihomotornih funkcija kod starijih (Bjelica i Krivokapić, 2012). Postoje naravno i osobe koje na pogrešan način upražnjavaju rekreativni sport i uopšte fizičku aktivnost, sa mišlju ili ubjeđenjima drugih da sve veća količina aktivnosti će dovesti i do većeg adaptivnog nivoa samog organizma. S toga, je jako bitno na pravi način informi- sati ljude o pravilnom načinu i količini vježbanja. Najpametniji, najoptimalniji i najvrijedniji trening je onaj koji kod svakog pojedinca omogućava da postigne ono što on može postići. (Bjelica i Fratrić, 2011). I ne samo to, sportska aktivnost - rekreacija čovjeku pruža da na slobodan način izabere onu fizičku aktivnost koju sam želi da upražnjava i koja ga čini srećnim.

Glavni cilj ovog rada je da provjeri nivo fizičke aktivnosti muškaraca starosne dobi od 50 do 69 godina, kao i da utvrdi postoji li razlika u nivou fizičkih aktivnosti muškaraca mlađih od 60 i starijih od 60 .

\section{Metod}

$\mathrm{U}$ ovom istraživanju uzorak ispitanika brojao je 100 osoba muške populacije, starosti od 50 do 69 godina. Uzorak je hronološki podijeljen na dva subuzorka. Prvi subuzorak čine osobe od 50 do 59 godina (njih 73), dok drugi subuzorak čine osobe od 60 do 69 godina (njih 27).

Od ukupnog broja ispitanika, njih 71 (71\%) je u radnom odnosu, a preostalih 29 (29\%) nije u radnom odnosu su penzionisani. Njih 97 stanuju u Podgorici, dvoje je iz Pljevalja, a jedan ispitanik sa Cetinja. Kada je u pitanju tip naselja u kojima žive, njih 92 žive u gradskom području, dok 8 žive u ostalim tipovima naselja.

Kriterijumi za uključivanje uzorka u ovo istraživanje, bili su: da osoba ima između 50 i 70 godina i da je muškog pola.

Tabela 1. Opšti podaci u uzorku

\begin{tabular}{ccc}
\hline GODINE STAROSTI & BROJ & PROCENAT (\%) \\
\hline $50-59$ & 73 & 73 \\
$60-69$ & 27 & 27 \\
UKUPNO & 100 & 100 \\
\hline
\end{tabular}

Fizička aktivnost muškaraca starosti od 50 do 69 godina provjerena je međunarodnim IPAQ upitnikom - International Physical Activity Questionnaires (Craig et al., 2003). Ovim upitnikom kroz 31 pitanje, procjenjivala se fizička aktivnost muškaraca na poslu, u prevozu, u domaćinstvu, kao i u slobodnom vremenu.

Nivo aktivnosti utvrđen je izračunavanjem Metabolic Equivalent Task (MET) za svaki tip fizičke aktivnosti posebno. Nedeljni obim fizičke aktivnosti (MET-min/week) dobijen je pojedinačnim zbrajanjem MET vrijednosti za svaku stavku.

Predložena su tri nivoa fizičke aktivnosti (niska, umjerena i visoka). Visoka fizička naprezanja odlikuju teški fizički poslovi na građevini, poljoprivredi i slično. Srednja ili umjerena fizičke aktivnosti karakterišu nošenje lakih tereta ili hodanje uz blaži uspon. Kod izračunavanja MET vrijednosti korišteni su koeficijenti: naporne fizičke aktivnosti = 8.0 METs; Srednje fizičke aktivno- sti $=4.0$ METs; Hodanje $=3.3$ METs

Prilikom statističke obrade podataka koristili smo deskriptivnu statistiku i izračunavanjem dobili aritmetičku sredinu i standardnu devijaciju za svaku varijablu. Da bi utvrdili postoji li statistički značajna razlika između mlađe i starije grupe, upotrijebljena je diskriminativna statistička analizaa, t-test na nivou značajnosti $\mathrm{q}=0.01$.

\section{Rezultati}

U tabeli 2. je prikazano koliko su muškarci trećeg doba bili fizički aktivni u proteklih nedelju dana. Posebna pažnja se posvetila aktivnostima na poslu, u domaćinstvu, prevozu i slobodnom vremenu. Takođe, prikazana je i statistički značajna razlika u nivou aktivnosti između dva subuzorka. Dobijena statistički značajna razlika vidi se kod sljedećih ukupnih fizič-

Tabela 2. Aktivnosti muškaraca trećeg doba u proteklih 7 dana

\begin{tabular}{lccc}
\hline & $\mathbf{5 0 - 5 9}$ & $\mathbf{6 0 - 6 9}$ & $\mathbf{n = 2 7}$ \\
\hline Ukupna fizička aktivnost na poslu (MET) & $\mathbf{n}$ & $\mathbf{q}$ & 0.00 \\
Ukupna fizička aktivnost u prevozu (MET) & $3445.72 \pm 4122.77$ & $3457.34 \pm 1629.73$ & 0.00 \\
Ukupna fizička aktivnost u domaćinstvu (MET) & $2365.74 \pm 1672.83$ & $1733.49 \pm 817.17$ & 0.00 \\
Ukupna fizička aktivnost u slobodnom vremenu (MET) & $307.74 \pm 145.02$ & $644.85 \pm 303.98$ & 0.00 \\
Ukupne aktivnosti hodanje (MET) & $3197.41 \pm 1507.27$ & $2477.56 \pm 1167.93$ & 0.00 \\
Ukupne umjerene aktivnosti (MET) & $3975.22 \pm 1873.93$ & $3616.56 \pm 1704.86$ & 0.00 \\
Ukupne naporne aktivnosti (MET) & $1957.88 \pm 922.95$ & $2101.31 \pm 973.59$ & 0.45 \\
Ukupne fizičke aktivnosti (MET) & $11803.61 \pm 5111.11$ & $5963.09 \pm 2582.09$ & 0.00 \\
\hline
\end{tabular}

MET-metabolička jedinica, q- statistički značajna razlika utvrđena t-testom 
kih aktivnosti: na poslu, u prevozu, domaćinstvu, slobodnom vremenu, umjerenim aktivnostima i kod zbrajanja svih fizičkih aktivnosti u protekoj nedelji.

\section{Diskusija}

Prethodna istraživanja nam ukazuju na činjenicu da fizička aktivnost kod muškaraca trećeg doba opada sa godinama (Mitrović, 2018; Masanovic, Vukotic, Bjelica, \& Popovic, 2018). Istraživanje koje je sprovedeno u centralnoj regiji Crne Gore, poklapa se sa dobijenim rezultatima ovog istraživanja. Tu se pokazalo da su muškarci trećeg doba, koji žive u Nikšiću, sa godinama manje fizički aktivni (Mitrović, 2018). Kada je u pitanju suprotan pol, rezultati istraživanja koja su sprovedena na teritoriji Podgorice, ukazuju da kod žena trećeg doba nije ni malo bolja situacija. Naprotiv, one su manje aktivne nego što su to bili muškarci u istom gradu. Takođe, dolazi do poklapanja rezultata koji se odnose na opadanje fizičkih aktivnosti sa godinama, oni ukazuju da žene koje pripadaju mlađem uzorku pokazuju bolje rezultate u fizičkoj aktivnosti u odnosu na stariju grupu (Ljumović, 2017). Ono što je veoma zapaženo kod istraživanja ovog tipa, jeste da bez obzira na pol ljudi trećeg doba su sa godinama sve manje aktivni (Popovic, Bjelica, Vukotic, \& Masanovic, 2018). Što još jednom potvrđuje činjenicu da se mora raditi na promovisanju fizičkih aktivnosti, pogotovo kod starijih osoba.

Možemo konstatovati da se dobijeni parametri ovog istraživanja, za fizičku aktivnost muškaraca u proteklih nedelju dana, veoma razlikuju u zavisnosti od aktivnosti koja je u pitanju. Kada govorimo o poslu, uzimajući u obzir da od ukupnog uzorka, u radnom odnosu je 71 muškarac, vidimo da su muškarci veoma fizički aktivni za vrijeme posla, više nego u bilo kojoj drugoj aktivnosti.

U fizičkoj aktivnosti koja se ogleda u prevozu, a gdje zbrajamo hodanje i vožnju bicikla, nije zastupljena značajna fizička aktivnost koja je na zadovoljavajućem nivou, što ukazuje na činjenicu da se ljudi više voze prevoznim sredstvima poput: automobila, autobusa, itd. Mada, rezultati fizičkih aktivnosti kod ukupnog hodanja, ukazuju na to da nije toliko niska pomenuta aktivnost, ali iz razloga jer imamo hodanje kod aktivnosti na poslu, gdje muškarci veći dio radnog vremena provedu na nogama.

Kada je u pitanju rad u domaćinstvu, najviše je zastupljen rad u dvorištu, ali rezultati ni tu nisu značajno visoki. Svakako da možemo uzeti u obzir i vrijeme, odnosno, godišnje doba anketiranja, jer je moguće da tada i nema toliko poslova u dvorištu i prilike za rad. Svakako još veću ulogu neaktivnosti zauzima činjenica da uglavnom svi ispitanici žive u gradskim zonama, te stoga je negdje i opravdan ovaj rezultat.

Slobodno vrijeme je jedan od najnižih parametara, slično kao i kod prevoza, što nam govori da muškarci trećeg starosnog doba slabo koriste fizičke aktivnosti - rekreaciju i da nisu fizički aktivni u slobodnom vremenu, već da većinu slobodnog vremena provode u sjedjenju i odmaranju.

Od ukupnih MET aktivnosti u hodanju, umjerenoj aktivnosti i napornoj aktivnosti vidimo da dominiraju umjerene aktivnosti, što znači da su muškarci trećeg starosnog doba najviše aktivni na tom nivou, zatim slijedi hodanje, dok naporne aktivnosti imaju najmanje parametre. Iz svih ovih rezultata, upoređujući međusobnu zavisnost subuzoraka, vidimo da postoji statistički značajna razlika između skoro svih parametara, kada je u pitanju fizička aktivnost, i to u korist mlađeg subuzorka. Izuzev ukupnih napornih aktivnosti nemamo statistič- ki značajnu razliku, uz činjenicu da je parametar kod starijeg subuzorka blago veći.

Iz svega navedenog, rezultati ukazuju da je čak u 5 od 7 varijabli fizički aktivniji subuzorak muškaraca koji je mlađi, što potvrđuje i ukupna fizička aktivnost koja se dobija zbrajanjem dobijenih parametara. Samo rezultati varijable koja pokazuje fizičke aktivnosti u slobodnom vremenu su dobijeni u korist starijeg uzorka, dok kod ukupnih napornih aktivnosti nemamo statistički značajnu razliku. Već navedene činjenice nam ukazuju na to da je aktivniji mlađi uzorak ispitanika, tj. da fizička aktivnost opada sa godinama.

Generalno, rezultati ovog istraživanja nisu ohrabrujući. Oni ukazuju na to da se mora raditi na probuđivanju svijesti o važnosti fizičke aktivnosti u slobodnom vremenu, podaci govore da se nekvalitetno provodi slobodno vrijeme. Nužno je povećavati fiskulturne sadržaje na nivou grada, kako bi na taj način pivukli što veći broj osoba, naročito starijih. Otvoriti više multifunkcionalnih sportsko - rekreativnih centara, adekvatnih i rehabilitacionih centara, kako bi pružili mogućnost da putem kineziterapije pomognemo i osobama koje nisu $u$ mogućnosti, da na bilo koji način (kao zdrava osoba) učestvuju i upražnjavaju fizičku aktivnost. Povećati nivo fizičke kulture u školama, kako bi se sistemski mislilo o budućnosti mlađih naraštaja, odnosno njihovim zrelijim godinama. Motivisati ljude da u vidu prevoznog sredstva koriste više šetnju ili bicikl, svakako da je područje glavnog grada uglavnom tokom cijele godine pod povoljnim vremenskim uslovima, sto može biti i motiv više da se posebno osobe trećeg doba odluče za šetnju. Ljudsko tijelo stvoreno je za pokret, a mi ga danas sve manje koristimo.

Svrha ovog rada sastojala se u tome da se utvrdi fizička aktivnost muskaraca trećeg doba na teritoriji Podgorice. Rezutati koje smo dobili ovim istraživanjem nam ukazuju na to da se mora raditi na promovisanju fizičke aktivnosti, pogotovo među populacijom trećeg doba. Ovo istraživanje može poslužiti za dalja istraživanja na ovom polju, a i u praktične svrhe kada je u pitanju organizovanje sadržaja koje bi uključivale osobe trećeg doba u više fizičkih aktivnosti, pogotovo ovih gdje su ispitanici najmanje aktivni.

\section{Acknowledgements}

There are no acknowledgements.

\section{Conflict of Interest}

The authors declare that there are no conflict of interest.

Received: 19 January 2018| Accepted: 22 March 2018| Published: 13 July 2018

\section{References}

Bjelica, D. (2002). Opšti pojmovi sportskog treninga: (skraćena verzija). Podgorica.

Bjelica, D. (2004). Uticaj sportskog treninga na antropomotoričke sposobnosti: (fudbalskih kadeta Crne Gore). Podgorica: Crnogorska sportska akademija.

Bjelica, D. (2005). Sistematizacija sportskih disciplina i sportski trening. Podgorica: Crnogorska sportska akademija.

Bjelica, D. (2006a). Sportski trening. Podgorica: Crnogorska sportska akademija.

Bjelica, D. (2006b). Teorijske osnove tjelesnog i zdravstvenog obrazovanja. Podgorica: Crnogorska sportska akademija.

Bjelica, D., i Fratrić, F. (2011a). Sportski trening: teorija, metodika i dijagnostika. Nikšić: Fakultet za sport i fizičko vaspitanje.

Bjelica, D., i Krivokapić, D. (2010). Teorijske osnove fizičke kulture. Nikšić: Fakultet za sport i fizičko vaspitanje Univerziteta Crne Gore.

Bjelica, D., i Krivokapić, D. (2011). Teorija igre. Nikšić: Fakultet za sport i fizičko vaspitanje Univerziteta Crne Gore. 
Bjelica D., i Krivokapić D. (2012). Uticaj fizičkog vježbanja na psihomotorne funkcije starijih osoba. Zbornik radova Druge međunarodne konferencije Sportske nauke i zdravlje, Banja Luka: Panevropski univerzitet APEIRON, 191-96.

Bjelica, D. (2013). Teorija sportskog treninga. Podgorica: Univerzitet Crne Go-

Findak, V. (2001). Metodika tjelesne i zdravstvene kulture. Zagreb: Školska Knjiga.

NCD Risk Factor Collaboration. (2017). Worldwide trends in body-mass index, underweight, overweight, and obesity from 1975 to 2016: a pooled analysis of 2416 populationbased measurement studies in 128.9 million children, adolescents, and adults [published online October 10 2017]. Lancet. doi: 10.1016/S0140-6736(17)32129-3

Masanovic, B., Vukotic, M., Bjelica, D., \& Popovic, S. (2018). Describing Physical Activity Profile of Older Montenegrin Males Using the International Physical Activity Questionnaire (IPAQ). In Book of Abstracts 15th International Scientific Conference on Transformation Process in Sport "Sport
Performance" (61), Podgorica: Montenegrin Sports Academy.

Milanović, Z., Pantelić, S., Sporiš, G., Krakan, I., \& Mudronja, L. (2012). Razlike u nivou tjelesne aktivnosti kod muškaraca i žena preko 60 godina života. U "21. ljetnja škola kineziologa Republike Hrvatske"(163-168). Zagreb: Hrvatski kineziološki savez.

Mitrović, M. (2018). Self-Reported and Objectively Measured Physical Activity of Males from 50 to 69 Years Old. Jaspe, 2(2), 99-101.

Popović, S., \& Bjelica, D. (2017). Effects of physical activity on social exclusion among older people: a literature review. In Conference Book of Abstract of the 8th Conference of HEPA Europe, "Modern Approaches to Physical Activity promotion and measurement" (122). Zagreb: HEPA Europe.

Popovic, S., Bjelica, D., Vukotic, M., \& Masanovic, B. (2018). Describing Physical Activity Profile of Older Montenegrin Females Using the International Physical Activity Questionnaire (IPAQ). In Book of Abstracts 15th International Scientific Conference on Transformation Process in Sport "Sport Performance" (60-61), Podgorica: Montenegrin Sports Academy. 